\title{
Bacillus subtilis JNUCC Isolated from Galchisokjeot: Draft Genome Sequence and $\alpha$-glucosidase and Tyrosinase Inhibitory Activities
}

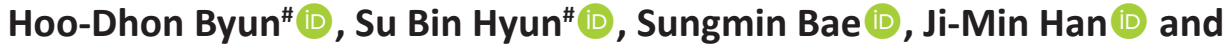 \\ Chang-Gu Hyun*
}

Department of Chemistry and Cosmetics, Jeju National University, Jeju, Republic of Korea.

\begin{abstract}
Bacterial strains isolated from fermented foods are gaining significance as they are reported to have antibacterial, antioxidant, and anticancer properties. $\alpha$-glucosidase is an essential enzyme in carbohydrate digestion and is the target of several anti-diabetic drugs. Tyrosinase catalyzes the rate-limiting reactions of melanin biosynthesis and hence its inhibitors are used as whitening agents. This study aimed to sequence the genome of Bacillus subtilis JNUCC isolated from Galchisokjeot, a traditional Korean fermented food from the Jeju region. It further investigated the potential use of its extract in controlling blood glucose levels and as a whitening agent. The genome of this strain was sequenced using the MiSeq System (Illumina Inc.). Different concentrations of the B. subtilis JNUCC extract were tested for $\alpha$-glucosidase and tyrosinase inhibition activities, using acarbose and arbutin as controls, respectively. The whole genome sequence of the strain contained 4,170,746 bp with 43.6\% GC content, 14 contigs and 4,338 genes. The half maximal inhibitory concentration (IC $\mathrm{C}_{50}$ ) values of the bacterial extract and the control against $\alpha$-glucosidase were $101.92 \mu \mathrm{g} / \mathrm{mL}$ and $204.58 \mu \mathrm{g} / \mathrm{mL}$, respectively. The $\mathrm{IC}_{50}$ values of the bacterial extract and the control against tyrosinase were $669.52 \mu \mathrm{g} /$ $\mathrm{mL}$ and $79.23 \mu \mathrm{g} / \mathrm{mL}$, respectively. Our study found that $B$. subtilis JNUCC extract showed two times higher $\alpha$-glucosidase inhibitory activity than that of acarbose and the inhibition was concentration dependent. Furthermore, although the tyrosinase inhibitory activity of the extract was weaker than that of arbutin, it was concentration-dependent. Thus, B. subtilis JNUCC has potential applications as an $\alpha$-glucosidase and tyrosinase inhibitor, and can be used in cosmetic and medicine industries.

Keywords: $\alpha$-glucosidase, Bacillus subtilis, genome, Inhibitor, Jeju, Tyrosinase
\end{abstract}

*Correspondence: cghyun@jejunu.ac.kr

\#Hoo-Dhon Byun and Su Bin Hyun contributed equally to this work.

(Received: February 27, 2020; accepted: March 20, 2020)

Citation: Hoo-Dhon Byun, Su Bin Hyun, Sungmin Bae, Ji-Min Han and Chang-Gu Hyun, Bacillus subtilis JNUCC Isolated from Galchisokjeot: Draft Genome Sequence and $\alpha$-glucosidase and Tyrosinase Inhibitory Activities, J. Pure Appl. Microbiol., 2020 14(1):189-193. https://doi.org/10.22207/JPAM.14.1.20

(c) The Author(s) 2020. Open Access. This article is distributed under the terms of the Creative Commons Attribution 4.0 International License which permits unrestricted use, sharing, distribution, and reproduction in any medium, provided you give appropriate credit to the original author(s) and the source, provide a link to the Creative Commons license, and indicate if changes were made. 


\section{INTRODUCTION}

Galchisokjeot is a traditional food of Jeju (Korea), containing approximately $25 \%$ salt mixed with small largehead hairtail (Trichiurus lepturus) and its guts, fermented by indigenous bacteria. In such traditional seafood preparations, the fermentation is aided by the high salt concentration and digestive enzymes of the fish or shellfish. The bacterial enzymatic activity improves the taste and flavor. These fermented foods are known to increase immunity, improve cholesterol levels, and have anti-cancer effects. In addition, metabolites of bacteria isolated from these traditional fermented foods are known to have various physiologically active substances that possess antibacterial, antioxidant, and anti-cancer activities. Strains isolated from fermented foods, which have potential use in food, cosmetics, and medicine, are easy to industrialize as they are Generally Recognized as Safe (GRAS). Moreover, the yield of the physiologically active substances produced by the bacteria can be maximized through genetic manipulation. The introduction of next generation sequencing has resulted in extensive genomic research that has made the identification of specific genes and gene clusters encoding the various physiologically active substances produced by bacteria easier, thus enabling genetic manipulation of these organisms for industrial use.

$\alpha$-glucosidase, localized in the small intestine, is an essential enzyme for the digestion of carbohydrates. It converts complex carbohydrates into absorbable monosaccharides such as glucose ${ }^{2}$. Inhibition of this enzyme results in unabsorbed carbohydrates, leading to a drop in the postprandial blood sugar levels ${ }^{3}$. $\alpha$-glucosidase inhibitors have been developed as treatments for metabolic disorders, such as insulin-independent diabetes, obesity, and hyperlipidemia. Long term use of $\alpha$-glucosidase inhibitors, such as acarbose, miglitol, and voglibose, developed and marketed as hypoglycemic drugs, have side effects such as bloating and vomiting ${ }^{4}$. Thus, research to develop better $\alpha$-glucosidase inhibitors is essential.

Melanin, a group of pigments responsible for brown, black, yellow, and red color, is biosynthesized from tyrosine through a complex process ${ }^{5}$. The most important steps in melanin biosynthesis are the tyrosinase-catalyzed oxidation of tyrosine to 3,4-dihydroxy-L-phenylalanine (DOPA) and subsequent DOPA to dopaquinone ${ }^{6}$. Melanocytes demonstrate high tyrosinase activity. Therefore, inhibitors of tyrosinase activity have been used as skin-lightening agents due to their whitening effects ${ }^{7}$.

Several strains of $B$. subtilis are known to have antimicrobial, antioxidant, and anticancer activities. This study aimed to sequence the genome of $B$. subtilis strain JNUCC isolated from Galchisokjeot and further investigate its potential application in controlling blood glucose levels and as a whitening agent via its inhibition of $\alpha$-glucosidase and tyrosinase enzymes, respectively.

\section{MATERIALS AND METHODS \\ Strain}

Bacteria used in this study is Bacillus subtilis JNUCC (KACC 92300P) that were isolated from Galchisokjeot, Korean traditional fermented seafood.

\section{Genome Sequence Analysis}

B. subtilis JNUCC cells were cultivated in LB broth (Difco, USA) for 3 days. Genomic DNA was extracted from these cells using the FastDNA Spin Kit for Soil (MP Biomedicals, USA). The DNA was quantitated by Qubit 2.0 Fluorometer using Qubit dsDNA HS Assay Kit (Invitrogen, USA) and Quant-iT PicoGreen dsDNA Assay Kit (Invitrogen, USA). The genome was sequenced using an MiSeq system (IIlumina Inc., USA) following by a paired-end sequencing protocol $(2 \times 300 \mathrm{bp})$ at ChunLab (Seoul, Korea). The reads obtained were assembled with SPAdes 3.1.18. The genome was annotated with the NCBI Prokaryotic Genome Annotation Pipeline. Extraction of Bioactive Compounds from $B$. subtilis

The $B$. subtilis JNUCC was cultured in a metabolite medium [ $1 \%$ glucose, $1 \%$ yeast extract, $\left.0.05 \% \mathrm{KH}_{2} \mathrm{PO}_{4}, 0.05 \%\left(\mathrm{NH}_{2}\right)_{4} \mathrm{SO}_{4}, \mathrm{pH} 7.2\right]$ under aerobic conditions at $30^{\circ} \mathrm{C}$ for one week. The culture medium was filtered through a $300 \mathrm{~mm}$ of filter paper (ADVANTEC, Japan) and an equal volume of ethanol was added to it. Then, only the supernatant was taken, concentrated under reduced pressure, and then freeze-dried.

\section{$\alpha$-glucosidase Inhibition Activity Assay}

The assay was performed as previously described10, with a few modifications. All the 
samples were first dissolved in distilled water and diluted to concentrations of $62.5,125,250$, 500 , and $1,000 \mu \mathrm{g} / \mathrm{mL}$. Acarbose, an oral antidiabetic drug, was used as control. The assay was conducted in a 96-well microtiter plate. In each well, $20 \mu \mathrm{L}$ of sample was incubated with $20 \mu \mathrm{L}$ of the aqueous solution of $\alpha$-glucosidase $(0.75$ unit $/ \mathrm{mL}$, Sigma) at $37^{\circ} \mathrm{C}$ for $5 \mathrm{~min}$. Then, $100 \mu \mathrm{L}$ of p-Nitrophenyl $\alpha$-D-glucopyranoside $(1.5 \mathrm{mM}$, Sigma) was added and the mixture incubated at $37^{\circ} \mathrm{C}$ for $25 \mathrm{~min}$. The reaction was stopped by addition $60 \mu \mathrm{L}$ of $1 \mathrm{M} \mathrm{Na}_{2} \mathrm{CO}_{3}$. The absorbance was measured at $405 \mathrm{~nm}$ on a plate reader (SUNRISE, TECAN). The percentage $\alpha$-glucosidase inhibition was calculated as follows:

$\%$ of inhibition $=($ Acontrol - Asample $) /$ Acontrol $\times 100$

\section{Tyrosinase Inhibition Activity Assay}

The assay was performed as previously described ${ }^{11}$, with a few modifications. All the samples were first dissolved in distilled water and diluted to concentrations of $62.5,125,250,500$, and $1,000 \mu \mathrm{g} / \mathrm{mL}$. Arbutin was used as control. Assays were conducted in 96-well microtiter plates. In each well, $20 \mu \mathrm{L}$ of sample was incubated with $5 \mu \mathrm{L}$ of the aqueous solution of tyrosinase from mushroom (2500 units $/ \mathrm{mL}$, Sigma) and 45 $\mu \mathrm{L}$ of potassium phosphate buffer $(0.1 \mathrm{M}, \mathrm{pH}$ 6.8) and incubated at $37{ }^{\circ} \mathrm{C}$ for $5 \mathrm{~min}$. Then, 70 $\mu \mathrm{L}$ of L-tyrosine $(2 \mathrm{mM})$ and $60 \mu \mathrm{L}$ of potassium phosphate buffer $(0.1 \mathrm{M}, \mathrm{pH} 6.8)$ were added to the mixture and incubated at $37^{\circ} \mathrm{C}$ for $25 \mathrm{~min}$. A

(A)

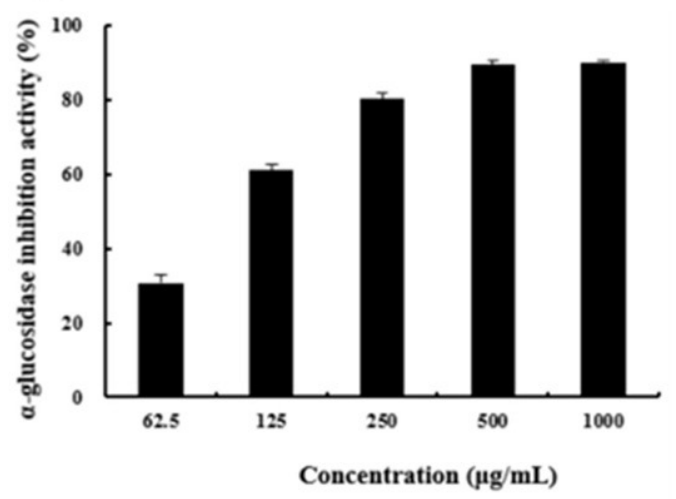

plate reader was used to measure absorbance at $480 \mathrm{~nm}$. The percentage tyrosinase inhibition was calculated as follows:

$\%$ of inhibition $=($ Acontrol - Asample $) /$ Acontrol $\times 100$

\section{Statistical analyses}

Data were presented as mean values \pm standard deviation. $I_{50}$ values were estimated by a nonlinear regression algorithm (SigmaPlot version 12.0).

\section{RESULTS AND DISCUSSION \\ Genome Sequence Analysis}

The whole genome sequence of $B$. subtilis JNUCC contains 4,170,746 bp with $43.6 \%$ GC content, and 14 contigs. The depth of coverage was 186.01-fold. The number of genes was 4,338, with 81 tRNAs, 21 rRNAs ( 8 of 5s rRNA, 9 of 16s rRNA, 4 of 23s rRNA). Protein-coding sequence (CDSs) were predicted 4,112 . This whole genome shotgun project has been deposited in GenBank under the accession no. VPFB00000000.

$\alpha$-glucosidase Inhibition Activity Assay

The extract of $B$. subtilis JNUCC at concentrations of $62.5,125,250,500$, and $1,000 \mu \mathrm{g} / \mathrm{mL}$, inhibited $\alpha$-glucosidase activity by $30.69 \%, 61.11 \%, 80.17 \%, 89.42 \%$, and $90.04 \%$, respectively (Fig. 1). The half maximal inhibitory concentration $\left(\mathrm{IC}_{50}\right)$ values for $B$. subtilis JNUCC extract and acarbose were $101.92 \mu \mathrm{g} / \mathrm{mL}$ and $204.58 \mu \mathrm{g} / \mathrm{mL}$, respectively. The extract of $B$. subtilis JNUCC was more effective than

(B)

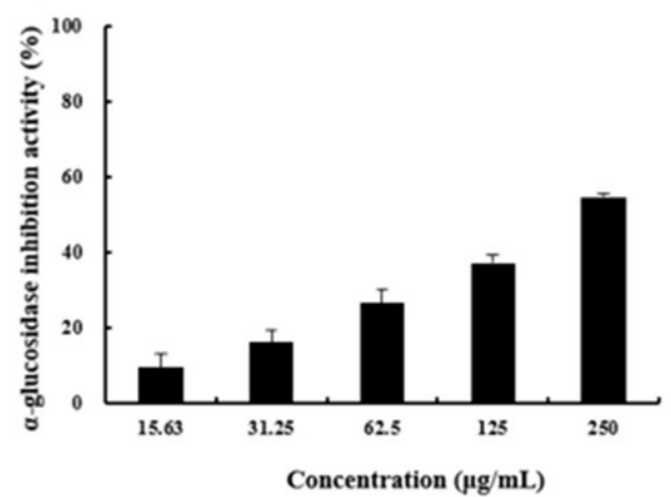

Fig. 1. $\alpha$-glucosidase inhibition activities of (A) extract of $B$. subtilis JNUCC and (B) acarbose. The appropriate amount of acarbose was used as a positive control. The inhibition of $p$-Nitrophenol, a reaction product produced by $\alpha$-glucosidase, was confirmed by measuring absorbance. The data are expressed as mean $\pm \operatorname{SD}(n=3)$. 
acarbose and inhibited $\alpha$-glucosidase activity in a concentration dependent manner. The $\alpha$-glucosidase, located in the small intestine, is an enzyme that converts carbohydrates into simple sugars such as glucose and is responsible for the increased blood sugar levels in individuals with diabetes mellitus type 2 . Commercially available $\alpha$-glucosidase inhibitors such as acarbose reduce the rate at which carbohydrates are broken down into glucose and thus prevent the rapid increase in blood sugar. Therefore, $\alpha$-glucosidase inhibitors can be used as a therapeutic agent for diabetes and obesity. In this study, we investigated whether B. subtilis JNUCC extract could be developed as $\alpha$-glucosidase inhibitor by comparing its inhibitory activity with that of acarbose. Our results suggest that the $B$. subtilis JNUCC extract can be potentially developed as an $\alpha$-glucosidase inhibitor.

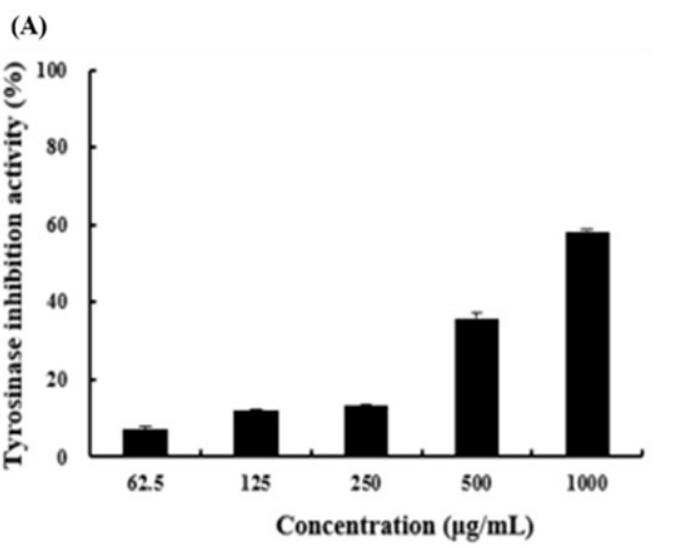

\section{Tyrosinase Inhibition Activity Assay}

The extract of $B$. subtilis JNUCC at concentrations of $62.5,125,250,500$, and 1,000 $\mu \mathrm{g} / \mathrm{mL}$ inhibited tyrosinase by $6.98 \%, 11.92 \%$, $13.50 \%, 35.75 \%$, and $58.19 \%$, respectively (Figure 2). The $I C_{50}$ values of extract of $B$. subtilis JNUCC and arbutin, which was used as control, were $669.52 \mu \mathrm{g} / \mathrm{mL}$ and $79.23 \mu \mathrm{g} / \mathrm{mL}$, respectively. Tyrosinase is the primary enzyme responsible for melanin production the skin. It catalyzes the oxidation of L-tyrosine, a substrate present in the body, to 3,4-dihydroxy-L-phenylalanine (DOPA) and the oxidation of DOPA to dopaquinone. Since the subsequent reactions in the melanin cascade occur spontaneously, the reaction catalyzed by tyrosinase determines the overall reaction rate. Therefore, tyrosinase inhibitory activity is an important factor for evaluating the whitening

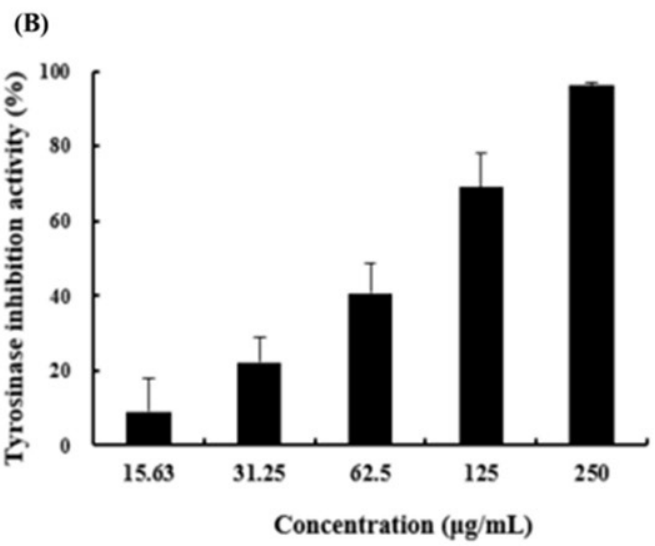

Fig. 2. Tyrosinase inhibition activities of (A) extract of $B$. subtilis JNUCC and (B) arbutin. The appropriate amount of arbutin was used as a positive control. The inhibition of DOPA Chrome, a reaction product produced by tyrosinase, was confirmed by measuring absorbance. The data are expressed as mean $\pm S D(n=3)$.

activity of several whitening agents. This study evaluated tyrosinase inhibitory activities of $B$. subtilis JNUCC extract and compared it with that of a known whitening ingredient, arbutin. Although the $B$. subtilis JNUCC extract showed weaker inhibitory activity than that of arbutin, its inhibition was concentration-dependent. This suggests that the extract of $B$. subtilis JNUCC had whitening activity. However, further studies are required to identify and isolate the key compounds in the bacterial extract responsible for this whitening effect and further elucidate their mechanism of action.

\section{CONCLUSION}

This study sequenced the genome of B. subtilis JNUCC isolated from Galchisokjeot, a traditional Korean fermented seafood from Jeju and demonstrated that the $B$. subtilis JNUCC inhibits $\alpha$-glucosidase and tyrosinase activities. Thus, it has potential applications in improving blood glucose levels in obesity and for use as a whitening agent.

\section{ACKNOWLEDGMENTS}

This research was supported by the Ministry of Trade, Industry \& Energy (MOTIE) 
and Korea Institute for Advancement of Technology(KIAT) through the UniversitiesIndustry Interaction Conference (No. N0002327).

\section{CONFLICT OF INTEREST}

The authors declare that there is no conflict of interest.

\section{FUNDING}

None.

\section{AUTHORS' CONTRIBUTION}

HDB and SBH contributed equally to this work. All authors listed have made a substantial, direct, and intellectual contribution to the work, and approved it for publication.

\section{DATA AVAILABILITY}

All datasets generated or analyzed during this study are included in the manuscript.

\section{ETHICS STATEMENT}

This article does not contain any studies with human participants or animals performed by any of the authors.

\section{REFERENCES}

1. Lee S, Kim S, II-Shik S. Studies on physiological activity of Bacillus subtilis JM-3 isolated from anchovy sauce. Korean J Food Sci Tech. 2003; 35: 684-689.

2. Kimura A, Lee JH, Lee IS, Lee HS, Park KH, Chiba S, Kim D. Two potent competitive inhibitors discriminating $\alpha$-glucosidase family I from family II. Carbohydr Res. 2004; 339 (6): 1035-1040. https://doi.org/10.1016/j. carres.2003.10.035
3.

Kumar S, Narwal S, Kumar V, Prakash O. $\alpha$-glucosidase inhibitors from plants: A natural approach to treat diabetes. Pharmacogn Rev. 2011; 5 (9): 19-29. https:// doi.org/10.4103/0973-7847.79096

4. Kim KY, Nam KA, Kurihara H, Kim SM. Potent alphaglucosidase inhibitors purified from the red alga Grateloupia elliptica. Phytochemistry. 2008; 69 (16): 2820-2825. https://doi.org/10.1016/j. phytochem.2008.09.007

5. Slominski A, Tobin DJ, Shibahara S, Wortsman J. Melanin pigmentation in mammalian skin and its hormonal regulation. Physiol Rev. 2004; 84 (4): 11551228. https://doi.org/10.1152/physrev.00044.2003

6. Hearing VJ, Jiménez M. Mammalian tyrosinase the critical regulatory control point in melanocyte pigmentation. Int J Biochem. 1987; 19 (12): 1141-1147. https://doi.org/10.1016/0020-711X(87)90095-4

7. Chlapanidas T, Faragò S, Lucconi G, Perteghella S, Galuzzi M, Mantelli M, Avanzini MA, Tosca MC, Marazzi M, Vigo D, Torre ML, Faustini M. Sericins exhibit ROS-scavenging, anti-tyrosinase, anti-elastase, and in vitro immunomodulatory activities. Int J Bio Macromol. 2013; 58: 47-56. https://doi.org/10.1016/j. ijbiomac.2013.03.054

8. Bankevich A, Nurk S, Antipov D, Gurevich AA, Dvorkin M, Kulikov AS, Lesin VM, Nikolenko SI, Pham S, Prjibelski AD, Pyshkin AV, Sirotkin AV, Vyahhi N, Tesler G, Alekseyev MA, Pevzner PA. SPAdes: a new genome assembly algorithm and its applications to single-cell sequencing. J Comput Biol. 2012; 19 (5): 455-477. https://doi.org/10.1089/cmb.2012.0021

9. Tatusova T, DiCuccio M, Badretdin A, Chetvernin V, Ciufo S, Li W. Prokaryotic genome annotation pipeline. The NCBI handbook [Internet], 2013; 2nd ed. NCBI, Bethesda, MD. https://www.ncbi.nlm.nih.gov/books/ NBK 174280.

10. Tibbot BK, Skadsen RW. Molecular cloning and characterization of a gibberellin-inducible, putative $\alpha$-glucosidase gene from barley. Plant Mol Biol. 1996; 30: 229-241. https://doi.org/10.1007/BF00020110

11. Yagi A, Kanbara T, Morinobu N. Inhibition of mushroomtyrosinase by aloe extract. Planta Med. 1987; 53 (06): 515-517. https://doi.org/10.1055/s-2006-962798 